\title{
Maternal and Neonatal Characteristics for Late Foetal Death in Latvia between 2001 and 2014: Population-Based Study
}

\author{
Irisa Zile $\mathbb{C}^{1},{ }^{1,2}$ Inguna Ebela, ${ }^{1}$ Valdis Folkmanis, ${ }^{1}$ and Ingrida Rumba Rozenfelde ${ }^{1}$ \\ ${ }^{1}$ Faculty of Medicine, Department of Paediatrics, University of Latvia, Raina bulv. 19, Riga LV-1586, Latvia \\ ${ }^{2}$ Department of Research, Statistics and Health Promotion, Centre for Disease Prevention and Control of Latvia, Duntes 22, \\ k-5, Riga LV-1005, Latvia \\ Correspondence should be addressed to Irisa Zile; irisazile@inbox.lv
}

Received 20 February 2018; Revised 21 June 2018; Accepted 4 July 2018; Published 18 July 2018

Academic Editor: Luca Marozio

Copyright (C) 2018 Irisa Zile et al. This is an open access article distributed under the Creative Commons Attribution License, which permits unrestricted use, distribution, and reproduction in any medium, provided the original work is properly cited.

\begin{abstract}
Introduction. Stillbirth is one of the most common adverse pregnancy outcomes worldwide. Late foetal death (LFD) rates are mostly used for international comparisons because of the large variations in stillbirth rates between countries. Objective. To examine trends in LFD (including antepartum and intrapartum) by multiple births, birth weight, and maternal age in two time periods. Methods. A retrospective cohort study was used to analyse data from the Medical Birth Register (2001-2014), divided into 2 periods of 7 years each. In total, data on 1,340 singletons were analysed. This study calculated LFD rates and rate ratios (RR). Results. The overall LFD rate showed a slight statistically significant reduction ( $\mathrm{p}<0.001)$ of $18 \%$ between 2001-2007 and 2008-2014. There was a slight increase in the mortality rate from multiple pregnancies (RR 1.1/1000; 95\% CI 0.6-1.9). There were no major differences in the LFD rate by maternal age during the time periods. Conclusions. LFD decreased (RR 0.8/1000 births), as well as intrapartum LFD (RR $0.6 / 1000$ births). Older maternal age influenced pregnancy outcomes, and higher LFD rates were observed in the age group $\geq 35$ years. Substantial intrapartum stillbirths rates indicate problems with quality of intrapartum care and emergency obstetric care. Further research is needed to evaluate the strategies necessary to substantially reduce the number of stillbirths in the country.
\end{abstract}

\section{Introduction}

Stillbirth is one of the most common adverse pregnancy outcomes worldwide; over 3 million deliveries annually are stillborn [1-4]. The European Perinatal Health Monitoring data (PERISTAT) analysis shows that the average reduction of stillbirths in 2010 compared to 2004 was approximately $19 \%$ (variations among countries to 38\%) [5,6]. Late foetal death rates are used for international comparisons because of large stillbirth rate variations between countries [7-9].

The number of stillbirths, which were explicitly targeted in the Millennium Development Goals, has decreased more slowly than has infant mortality or mortality in children younger than 5 years. The Every Newborn Action Plan has a target of 12 or fewer stillbirths per 1000 births in every country by 2030. A total of 94 mainly high-income countries and upper-middle-income countries have already met this target, although with noticeable disparities [3].

Variations in stillbirth rates across high-income countries and large equity gaps within high-income countries persist [10]. Disadvantaged women, those with less antenatal care and those who delivered without a skilled birth attendant were at increased risk of delivering a stillbirth [3,11, 12]. Each death is a tragic loss and causes much grief to the parents and extended family. These deaths matter to the mother and the family, to society, and to the health care system. Stillbirths are associated with public health challenges such as social inequalities, maternal obesity, and smoking [13].

Total stillbirth rates in Latvia have seen little change in the past 16 years. A slight decrease has been observed from $7.0 / 1000$ births in 2001 to $5.7 / 1000$ births in 2016 [14]. The aim of this study was to examine trends in late foetal death (including antepartum and intrapartum) by multiple births, birth weight, and maternal age in two time periods.

\section{Materials and Methods}

The study was a population-based registry study. Data were obtained from the Medical Birth Registry. All births in 
Latvia (including stillbirths) are compulsorily reported to the registry, and notification is made by standardized medical record forms used by all maternity units across the country. Late foetal deaths were defined as stillbirths occurring after 28 completed weeks of gestation and weighing at least $500 \mathrm{~g}$. In total, the data on 1,340 LFD cases were analysed from 2001 to 2014 , divided into 2 periods of 7 years each (2001-2007 and 2008-2014).

Descriptive statistics for all of the continuous variables (maternal age, foetal birth weight, and gestational week) are reported as medians, indicating the 25 th and 75 th percentiles. Categorical data are reported as percentages and 95\% confidence intervals (CI). The categorical variables were compared using chi-square tests. $\mathrm{P}$ values $<0.05$ were considered statistically significant.

The study described and compared maternal and antenatal care factors (including complete care, lack of antenatal care, and delayed antenatal care, i.e., the first visit after the 12th gestational week $(\mathrm{GW})$ ) and certain complications over the 2 time periods. Antenatal care quality was defined by three groups: without care (cases with LFD when mother has not been registered to gynaecology for antenatal care and therefore did not receive any antenatal checks), complete care (first antenatal visit till 12th week of pregnancy and totally 7 obligatory antenatal visits with all necessary antenatal checks and tests as per guidelines (blood, urine tests; ultrasound screening; genetic tests; etc.), and incomplete (one or more conditions are missing, e.g., late first antenatal visit or less antenatal visits or checks).

Maternal age was coded as follows: $\leq 19$ years, $20-34$ years, and $\geq 35$ years.

Late foetal death rates were calculated per 1000 total births in each time period. Time trends were analysed by calculating rate ratios (RR) with 95\% confidence intervals (CI), and rates in 2001-2007 were compared with those in 2008-2014.

The study was conducted with the approval of the Ethics Committee of the University of Latvia.

\section{Results}

A total of $74 \%$ of all stillbirths from 2001 to 2014 were late foetal deaths $(\mathrm{n}=1,340)$. The median maternal age in the surveyed population was 28 years (23-33), the median birth weight was $2380 \mathrm{~g}$ (1620-3100), and the median gestational week was 36 (32-39). There were no differences in medians by time periods. $55 \%(\mathrm{n}=732)$ was preterm birth. More than half were antepartum stillbirths, there was an increase $(p<0.001)$ between the 2 time periods. Intrapartum stillbirths make quite a large proportion although decrease by 6.1 percentage points ( $\mathrm{p}<0.001$ ) was observed over time $(22.8 \%$ to $16.7 \%)$. There were no changes detected in LFD by gestational age and birth weight (Table 1).

An analysis of antenatal care factors that may be associated with adverse pregnancy outcomes found that a total of $29.0 \%$ (95\% CI 26.7-31.5) of stillbirths occurred in cases of late registration for antenatal care (after $12 \mathrm{GW}$ ). However, in those time periods, a decrease of 13 percentage points was observed $(\mathrm{p}<0.001)$. In comparing antenatal care quality at 2 time points, there was also an observed decrease in the proportion of mothers who were without antenatal care-from $18.3 \%$ (95\% CI $15.7-21.2)$ to $10.6 \%$ (95\% CI 8.3 13.2) $(\mathrm{p}<0.001)$. There were no statistically significant changes by incomplete antenatal care (17.1\% (95\% CI 14.5 20.1 ) to $15.6 \%$ (95\% CI 12.8-18.6)), but complete antenatal care grew from $64.5 \%$ to $73.8 \%$ ( $\mathrm{p}<0.001$ ). Intrauterine growth restriction detected antenatally was observed in $3.8 \%(n=51)$, pregnancy-induced hypertension $5.5(\mathrm{n}=74)$, preeclampsia $6.5 \%(n=87)$, and placenta abruption $5.7 \%(n=77)($ Table 1$)$.

Smoking during pregnancy was observed in a total of $20.3 \%$ (95\% CI 18.2-22.5) of cases, and a slight decrease by 3.8 percentage points in smoking was observed over time; however, this difference was not statistically significant (Table 1).

Total numbers of births, live births, and LFD rates in different study time points are given in Table 2 . Totally an average is 20,000 births a year. The overall late foetal death rate showed a slightly statistically significant reduction $(p<$ 0.001 ) of $18 \%$ between 2001-2007 and 2008-2014. Decrease was observed also in intrapartum LFD (RR 0.6/1000 births). There were no major differences in the late foetal death rate by maternal age during the time periods. A more substantial reduction was observed in the age group $\geq 35$ years $(p<0.001)$.

\section{Discussion}

Nearly 2.6 million stillbirths occur globally each year, most of which are thought to be preventable. The majority of these deaths occurred in developing countries. About half of all stillbirths occur in the intrapartum period, representing the greatest time of risk [1].

The results of the present study showed that an average of $80 \%$ of stillbirths are antepartum deaths. Our study findings indicate an indirect association between late and inadequate antenatal care and stillbirths. Our previous studies observed that the single largest risk factor for antepartum stillbirth is foetal growth restriction [15]. Preventive strategies need to focus on improving antenatal detection of foetal growth restriction $[16,17]$.

The intrapartum death rate of a country is reflective of the care received by mothers and babies in labour and rate higher than $10 \%$ indicates problems with obstetric care quality [17]. The number of intrapartum foetal deaths that occur in high-income countries on average is $0.3-0.7 / 1000$ births $[3,4]$. Our study showed higher intrapartum LFD rate although slightly decreased till $0.7 / 1000$ in the second time point. Intrapartum stillbirths are largely preventable with quality intrapartum care, including prompt recognition and management of intrapartum complications [17]. Therefore antenatal care also plays a vital role in the management of a woman's health during pregnancy, and women who have not been registered to antenatal care are at an increased risk of intrapartum stillbirth too.

This study found that a very high proportion of LFD was related to a late first antenatal visit or incomplete care. Nevertheless, a positive decreasing tendency for late antenatal visits has been observed in the study period, from 2001 to 2014. High proportion was found for LFD cases and lack 
TABLE 1: Comparison of maternal and neonatal characteristics of LFD in 2001-2007 and 2008-2014.

\begin{tabular}{|c|c|c|c|}
\hline Characteristics & $\begin{array}{c}\text { 2001-2007 } \\
\text { No }(\%(95 \mathrm{CI}))\end{array}$ & $\begin{array}{c}\text { 2008-2014 } \\
\text { No }(\%(95 \mathrm{CI}))\end{array}$ & p value \\
\hline Mean maternal age $^{1}$ & $28(23-33)$ & $28(24-33)$ & NS \\
\hline Mean gestational week ${ }^{1}$ & $36(32-39)$ & $36(32-39)$ & NS \\
\hline Mean birth weight $(\mathrm{g})^{1}$ & $2340(1660-3046)$ & $2405(1550-3170)$ & NS \\
\hline Antepartum & $568(77.2(74.0-80.1))$ & $503(83.3(80.2-86.1))$ & $<0.001$ \\
\hline Intrapartum & $168(22.8(19.9-26.0))$ & $101(16.7(13.9-20.0))$ & $<0.001$ \\
\hline \multicolumn{4}{|l|}{ Maternal age groups ${ }^{2}$} \\
\hline$\leq 19$ years & $65(8.8(7.0-11.1))$ & $38(6.3(4.6-8.4))$ & NS \\
\hline 20-34 years & $521(70.8(67.6-74.2))$ & $439(72.7(69.0-76.1))$ & NS \\
\hline$\geq 35$ years & $150(20.4(17.6-23.5))$ & $127(21.0(17.9-24.4))$ & NS \\
\hline \multicolumn{4}{|l|}{ Gestational age, weeks ${ }^{2}$} \\
\hline $28-31$ weeks & $158(21.5(18.6-24.5))$ & $130(21.5(18.4-25.0))$ & NS \\
\hline $32-36$ weeks & $247(33.6(30.2-37.0))$ & $197(32.6(29.0-36.4))$ & NS \\
\hline$\geq 37$ weeks & $331(45.0(41.4-48.6))$ & $277(45.9(42.0-50.1))$ & NS \\
\hline \multicolumn{4}{|l|}{ Birth weight groups, $g^{2}$} \\
\hline $500-1499 \mathrm{~g}$ & $140(19.0(16.3-22.0))$ & $140(23.2(19.9-26.7))$ & NS \\
\hline $1500-2499 \mathrm{~g}$ & $270(36.7(33.3-40.2))$ & $173(28.6(25.1-32.4))$ & NS \\
\hline$\geq 2500 \mathrm{~g}$ & $326(44.3(40.7-47.9))$ & $291(48.2(44.2-52.2))$ & NS \\
\hline Multiple births ${ }^{2}$ & $33(4.5(3.2-6.2))$ & $40(6.6(4.8-8.8))$ & NS \\
\hline Late first antenatal visit (after $12 \mathrm{GW})^{2}$ & $257(34.9(31.5-38.4))$ & $132(21.9(18.7-25.3))$ & $<0.001$ \\
\hline Smoking during pregnancy ${ }^{2}$ & $162(22.0(19.1-25.1))$ & $110(18.2(15.3-21.4))$ & NS \\
\hline Foetal growth restriction $^{2}$ & $24(3.3(2.1-4.7))$ & $27(4.5(3.0-6.3))$ & NS \\
\hline Pregnancy-induced hypertension ${ }^{2}$ & $39(5.3(3.8-7.1))$ & $35(5.8(4.1-8.0))$ & NS \\
\hline Preeclampsia $^{2}$ & $46(6.3(4.7-8.2))$ & $41(6.8(5.0-9.0))$ & NS \\
\hline Placenta abruption ${ }^{2}$ & $56(7.6(5.9-9.7))$ & $21(3.5(2.2-5.2))$ & $<0.001$ \\
\hline
\end{tabular}

${ }^{1}$ Represents median (25th and 75th percentile) and Mann-Whitney $\mathrm{U}$ test is used.

${ }^{2}$ Represents n (\% (95\% CI)) and Chi-square test is used; NS: Not Significant.

TABLE 2: The birth and LFD statistics in 2001-2007 and 2008-2014.

\begin{tabular}{lccc}
\hline & $\mathbf{2 0 0 1 - 2 0 0 7}$ & $\mathbf{2 0 0 8 - 2 0 1 4}$ & Rate ratio (95\% CI) \\
\hline Total birth number & 147365 & 143466 & 144043 \\
Number of live births & 147573 & 604 & $0.8(0.2-1.9)$ \\
Number of LFD & 736 & 4.2 & $0.9(0.9-1.2)$ \\
LFD* & 5.0 & 3.5 & $0.6(0.3-1.0)$ \\
LFD antepartum & 3.8 & 0.7 & $1.1(0.6-1.9)$ \\
LFD intrapartum & 1.1 & 11.3 & $1.0(0.3-2.4)$ \\
LFD by multiple births & 10.2 & 4.5 & $0.9(0.2-2.0)$ \\
LFD by maternal age: & & 3.9 & $0.6(0.2-1.2)$ \\
$\leq 19$ years & 4.7 & 5.8 & \\
$20-34$ years & 4.4 & 9.2 & \\
$\geq 35$ years &
\end{tabular}

${ }^{*}$ LFD (late foetal death) rates were calculated per 1000 total births (live and still).

of antenatal care, an average $15 \%$. According to statistical data in the general population in $2016,0.7 \%$ of live births occurred without antenatal care, but the rate of stillbirths that occurred without prenatal care was 8 times higher, at $6.2 \%$ [18]. We have limited information in the Medical Birth Register about maternal smoking habits, but the study data indicate that the proportion of maternal smoking related to LFD was an average of $20 \%$. Smoking during pregnancy showed a slight but nonsignificant decrease, from $22 \%$ to $18 \%$. Statistical data in Latvia shows that maternal smoking related to live births was $7.6 \%$ and $9.3 \%$ for stillbirths in 2016 [18]. Indisputably, prenatal care plays an important role in 
the monitoring and control of both sociodemographic and lifestyle factors, which may contribute to poor pregnancy outcomes including stillbirths $[3,11,13,19]$.

As shown in the literature, the number of neonatal and infant deaths declined more rapidly than the number of stillbirths $[1-3,20]$. Foetal and neonatal mortality rates are highly sensitive to inclusion criteria for threshold gestational age and birth weight, especially in comparison to other countries $[7,9]$. However, it is no less important to obtain national data and trend analysis within the country because perinatal, foetal, and neonatal mortality statistics are also important to show the development of the health care system. Our country has limited epidemiological studies about stillbirths and late foetal death. For this reason, our research aim was to evaluate trends in late foetal death (including antepartum and intrapartum period) by multiple births, birth weight, and maternal age in two time periods to better understand and obtain more population-based data on this issue.

During the study period of 2001-2014, the overall late foetal death rate declined by $18 \%$. Similar findings were obtained in the PERISTAT data analysis; between 2004 and 2010 , stillbirths declined by $17 \%$, with a range from $1 \%$ to $39 \%$ by country [6]. The perinatal health monitoring system shows that the foetal mortality rates at or after 28 weeks of gestation ranged from lows under 2.0 per 1000 live births and stillbirths in the Czech Republic and Iceland to 4.0 or more per 1000 live births in countries such as France and Latvia [5].

A survey using the PERISTAT data indicated that stillbirth rates in European countries declined in all gestational age subgroups. Declines were lower for stillbirths at 28-31 weeks (12\%) than at 32-36 weeks (19\%) and 37 weeks and over (18\%) [6]. There were no changes by LFD within gestational age groups by time period in our study. The high proportion of LFD was from term births (45\%). These results underscore the importance of a focus on improving outcomes across the gestational age spectrum.

The study results show that LFD rates were higher in multiple births and in the maternal age group $\geq 35$ years, although a more rapid decrease of $15 \%$ was observed in that age group in the 2 time periods. Other study results that analysed more risk factors indicated that LFD rates were increased in women who were 35 years or older [3, 8, 12, 21].

In recent years, the health of mothers and children in Latvia has been receiving increasing attention; thus, different solutions for improving the situation have been closely evaluated. Maternal and child health improvement and the reduction of mortality rates are also two of the objectives stated in the "Public Health Strategy for 2011-2017" [22] and the project document "Maternal and Child Health Improvement Plan 2018-2020" [23], developed by the Ministry of Health. The Action Plan also foresees changes in the legislative documents in screening policies, and improvements are being made in the implementation of perinatal audits in clinical practice and at the national level [23]. Quality of care includes the judgement to determine which women are at risk and require interventions. However, in addition to the quality of obstetric care, the timeliness of providing obstetric care is critical, especially to save the foetus. Tools such as perinatal audits have been shown to improve the quality of facility care and to reduce stillbirth [24, 25]. Substantial proportion of intrapartum stillbirths (higher than 10\%) are preventable with quality intrapartum care and emergency obstetric care can make the greatest impact on stillbirth rates $[3,17]$. Study data of intrapartum stillbirths rate highlight problems with accessibility and quality of the health care system in the field of antenatal and obstetric care. Improvement needs in Latvian healthcare system were documented also from international organizations (European Commission and the World Bank). For instance, there is a need to consider developing clinical guidelines and pathways based on clear criteria and standardized methods; improve quality of service provision, and coordination of services among healthcare providers and emerging legislation and regulatory frameworks [26].

Further work should be done to analyse and audit intrapartum death cases to identify areas of obstetric care for improvement. In 2017 improvements have been made in obstetric care, for instance, defined a procedure for the identification of high-risk patients and risk management; action plan and management of care in cases with common childbirth complications; obligatory maternal and perinatal audit in medical institutions etc.) [27].

The main strength of the study includes the fact that the data were population-based. This kind of epidemiological data is essential for health care planning and for determining temporal trends. The limitation is the lack of a comparison group of live births, which could be useful to determine other risk factors of LFD. Future research must focus on the causes of stillbirth. The results of this study may deserve attention for policy implementation regarding strategies to improve antenatal and obstetric labour and delivery care for women, in order to substantially reduce the number of stillbirths and strengthen perinatal audits at the national level.

\section{Conclusions}

The overall LFD rate showed a slight statistically significant reduction $(\mathrm{p}<0.001)$ over the study periods $(2001-2007$ and 2008-2014). Intrapartum LFD slightly decreased (RR 0.6/1000 births). Substantial intrapartum stillbirths rates indicate problems with quality of intrapartum care and emergency obstetric care. Further research is needed to evaluate the strategies necessary to essentially reduce the number of stillbirths in the country and to provide detailed analysis of LFD causes. Improvement in female literacy, health education, identifying high-risk pregnancies, and periodic audits of all stillbirths can help in reduction of stillbirths.

\section{Data Availability}

The data used to support the findings of this study were provided by The Centre for Disease Prevention and Control (CDPC) of Latvia under license and so cannot be made freely available. Access to these data will be considered by the author upon request with permission.

\section{Additional Points}

This work was supported by National Research Programme Biomedicine for Public Health (BIOMEDICINE). Research 
on acute and chronic diseases in a wide age range of children helps to develop diagnostic and therapeutic algorithms to reduce mortality, prolong survival, and improve quality of life.

\section{Conflicts of Interest}

The authors declare that there are no conflicts of interest regarding the publication of this paper.

\section{Acknowledgments}

The authors would like to thank the Centre for Disease Prevention and Control (CDPC) of Latvia for providing data.

\section{References}

[1] A. Martin, A. Connelly, R. M. Bland, and J. J. Reilly, "Health impact of catch-up growth in low-birth weight infants: systematic review, evidence appraisal, and meta-analysis," Maternal \& Child Nutrition, vol. 13, no. 1, 2017.

[2] Neonatal and perinatal mortality: country, regional and global estimates, World Health Organization, 2006.

[3] J. E. Lawn, H. Blencowe, P. Waiswa et al., "Stillbirths: rates, risk factors, and acceleration towards 2030," The Lancet, vol. 387, no. 10018, pp. 587-603, 2016.

[4] A. C. Breeze and C. C. Lees, "Intrapartum deaths: missed opportunities," Obstetrics, Gynaecology \& Reproductive Medicine, vol. 19, no. 6, pp. 164-168, 2009.

[5] European Perinatal health report, Health and Care of Pregnant Women and Babies in Europe in, 2010.

[6] J. Zeitlin, L. Mortensen, M. Cuttini et al., "Declines in stillbirth and neonatal mortality rates in Europe between 2004 and 2010: results from the Euro-Peristat project," Journal of Epidemiology \& Community Health, vol. 70, no. 6, pp. 609-615, 2016.

[7] A. D. Mohangoo, B. Blondel, M. Gissler et al., "International comparisons of fetal and neonatal mortality rates in highincome countries: should exclusion thresholds be based on birth weight or gestational age?" PLoS ONE, vol. 8, no. 5, Article ID e64869, 2013.

[8] V. Flenady, P. Middleton, and G. C. Smith, "Stillbirths: the way forward in high-income countries," The Lancet, vol. 377, no. 9778, pp. 1703-1717, 2011.

[9] A. D. Mohangoo, S. E. Buitendijk, K. Szamotulska et al., "Gestational age patterns of fetal and neonatal mortality in Europe: Results from the Euro-Peristat project," PLoS ONE, vol. 6, no. 11, Article ID e24727, 2011.

[10] V. Flenady, A. M. Wojcieszek, P. Middleton et al., "Stillbirths: recall to action in high-income countries," The Lancet, vol. 387, no. 10019, pp. 691-702, 2016.

[11] E. M. McClure, S. Saleem, S. S. Goudar et al., "Stillbirth rates in low-middle income countries 2010 - 2013: A population-based, multi-country study from the Global Network," Reproductive Health, vol. 12, no. 2, article no. s7, 2015.

[12] M. Aminu, R. Unkels, M. Mdegela, B. Utz, S. Adaji, and N. van den Broek, "Causes of and factors associated with stillbirth in low- and middle-income countries: a systematic literature review," BJOG: An International Journal of Obstetrics and Gynaecology, vol. 121, pp. 141-153, 2014.
[13] J. Gardosi, S. Giddings, S. Buller, M. Southam, and M. Williams, "Preventing stillbirths through improved antenatal recognition of pregnancies at risk due to fetal growth restriction," Public Health, vol. 128, no. 8, pp. 698-702, 2014.

[14] The Centre for Disease Prevention and Control (CDPC) of Latvia, https://www.spkc.gov.lv/upload/Veselibas\%20aprupes\% 20statistika/Statistikas\%20dati/2016/mirstiba_par_2016_v2.doc.

[15] I. Zile, I. Ebela, and I. Rumba-Rozenfelde, "The relationship of intrapartum and antepartum stillbirth rates in Latvia a retrospective cohort study," in Program and Abstracts, p. 143, 2014.

[16] A. C. G. Breeze and C. C. Lees, "Prediction and perinatal outcomes of foetal growth restriction. Semin Foetal Neonatal Med," C.C. Lees. Prediction and perinatal outcomes of foetal growth restriction. Semin Foetal Neonatal Med, vol. 12, pp. 383397, 2007.

[17] G. L. Darmstadt, M. Yakoob, R. A. Haws, E. V. Menezes, T. Soomro, and Z. A. Bhutta, "Reducing stillbirths; interventions during labour," BMC Pregnancy and Childbirth, vol. 9, no. 1, article s6, 2009.

[18] "Maternal and infant health care," in The Centre for disease prevention and control of Latvia, Statistical yearbook of health care in Latvia, 18th edition, 2017.

[19] E. M. Okoroh, D. V. Coonrod, K. Chapple, and D. Drachman, "Are neonatal morbidities associated with no prenatal care different from those associated with inadequate prenatal care?" Open Journal of Obstetrics and Gynecology, vol. 02, no. 02, pp. 89-97, 2012.

[20] N. Kültürsay, N. Aşkar, D. Terek et al., “The Change of Perinatal Mortality Over Three Decades in a Reference Centre in the Aegean Region: Neonatal Mortality has decreased but Foetal Mortality Remains Unchanged," Balkan Medical Journal, vol. 34, no. 6, pp. 553-558, 2017.

[21] S. Cnattingius, B. Haglund, and M. S. Kramer, "Differences in late fetal death rates in association with determinants of small for gestational age fetuses: Population based cohort study," British Medical Journal, vol. 316, no. 7143, pp. 1483-1487, 1998.

[22] Ministry oh Health of the Republic of Latvia, Public Health strategy for 2011 - 2017, No 504, (05.10.2011.).

[23] The Cabinet of Ministers of the Republic of Latvia, draft of Maternal and Child Health Improvement Plan 2018 - 2020.

[24] R. Pattinson, K. Kerber, P. Waiswa et al., "Perinatal mortality audit: Counting, accountability, and overcoming challenges in scaling up in low- and middle-income countries," International Journal of Gynecology \& Obstetrics, vol. 107, no. Supplement, pp. S113-S122, 2009.

[25] P. Stratulat, A. Curteanu, T. Caraus, V. Petrov, and J. Gardosi, "The experience of the implementation of perinatal audit in Moldova," BJOG: An International Journal of Obstetrics and Gynaecology, vol. 121, pp. 167-171, 2014.

[26] A. Hola, T. S. Rabie, and L. Sales, Prospects for Health Sector Reform in Latvia, World Bank, November 2016, http://www .vmnvd.gov.lv/uploads/files/585933cbld0d4.pdf.

[27] Cabinet Regulation No. 611. Obstetric procedures for ensuring (25.07.2006., modified in 2017). 


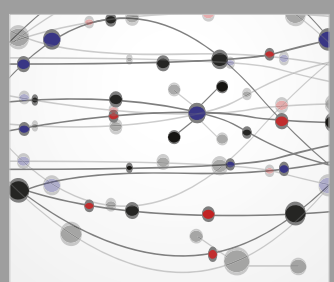

The Scientific World Journal
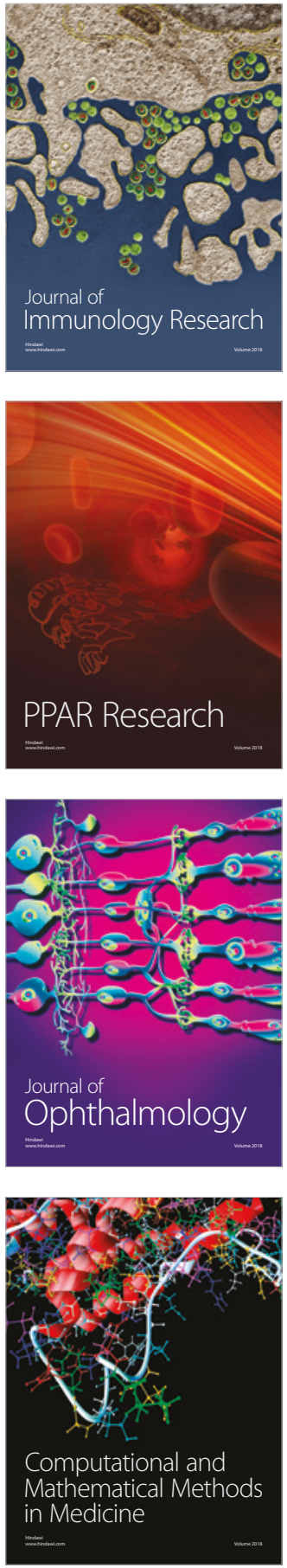

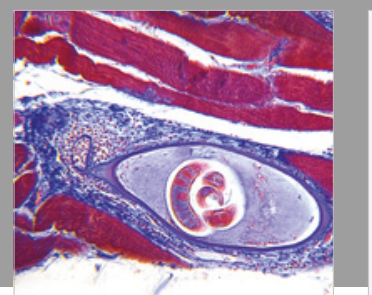

Gastroenterology Research and Practice

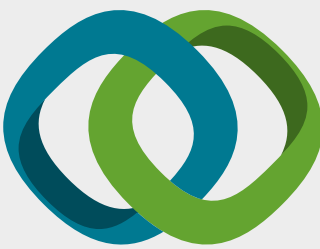

\section{Hindawi}

Submit your manuscripts at

www.hindawi.com
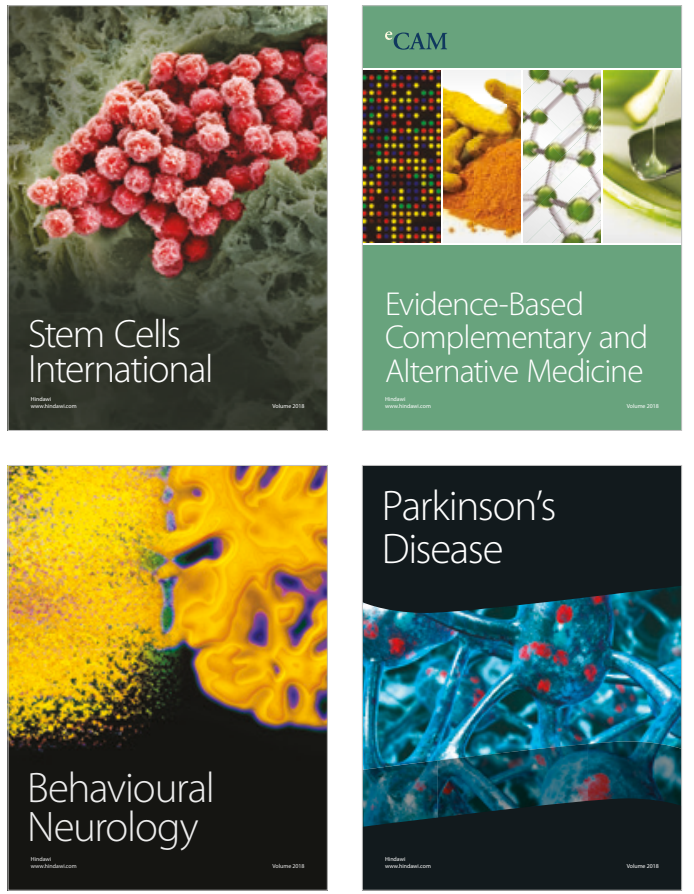

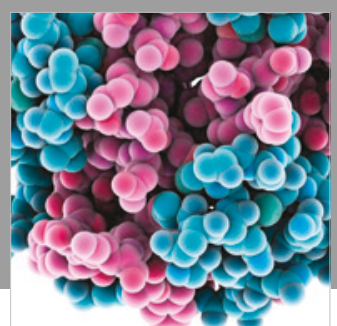

ournal of

Diabetes Research

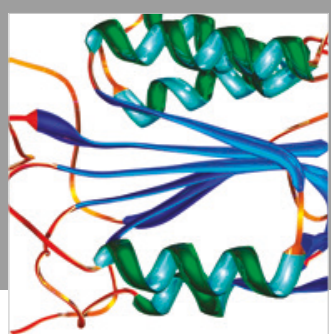

Disease Markers
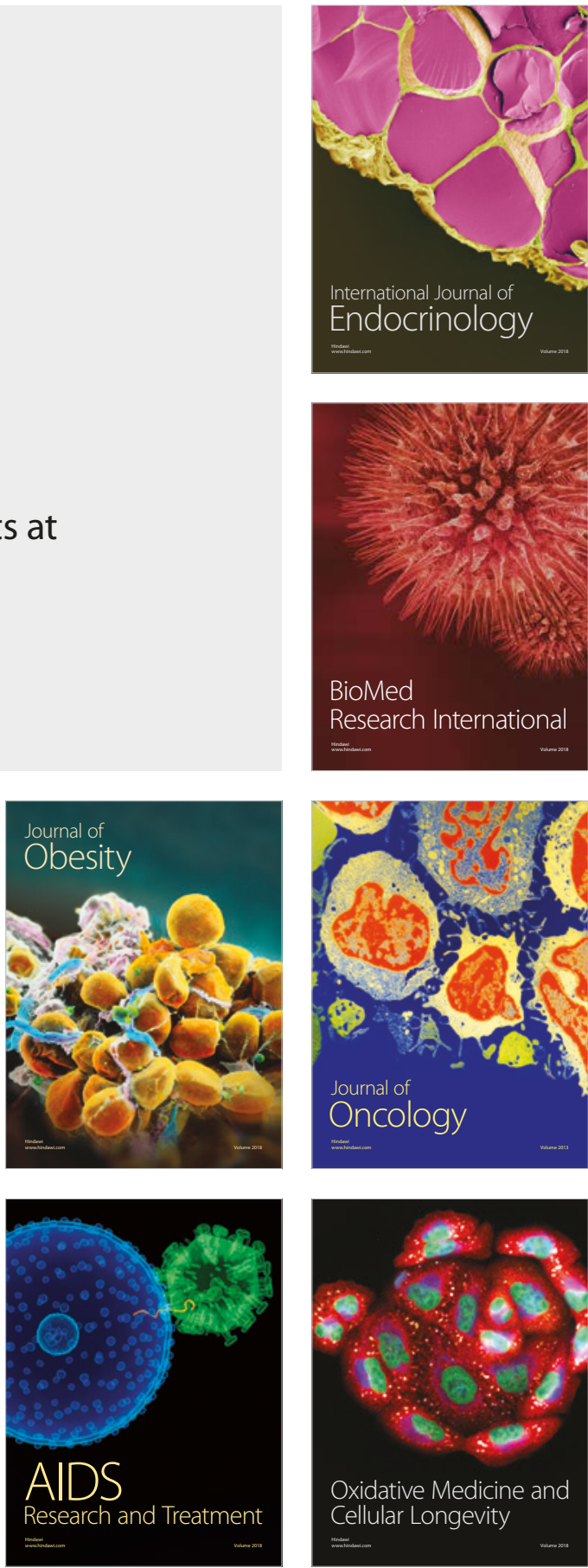